\title{
Chapter 2 \\ Classic Design of Curriculum Innovations: Investigation of Teacher Involvement in Research, Development, and Diffusion
}

\author{
Natalie Pareja Roblin and Susan McKenney
}

\section{Introduction}

The improvement of educational practice through research is a topic of ongoing debate. In education and other fields, the last decades have witnessed a renaissance of interest in knowledge mobilization and research use, and particularly in the role of empirical evidence in informing practice (Farley-Ripple, May, Karpyn, Tilley, \& McDonough, 2018; Levin, 2013; Nutley, Jung, \& Walter, 2009). However, despite this renewed interest, various studies have suggested that relationships between research and practice in education remain rather weak (e.g., HemsleyBrown \& Sharp, 2003; Vanderlinde \& van Braak, 2010). Multiple reasons have been identified in the literature to explain why these relationships are so difficult to build (cf. Broekkamp \& Van Hout-Wolters, 2007; Burkhardt \& Schoenfeld, 2003; Kennedy, 1997). One reason pertains to the relevance of educational research for classroom practice. It is often argued that the types of problems addressed by educational researchers are typically different from the types of problems experienced by teachers in their daily work, and therefore lack practical meaning (Broekkamp \& Van Hout-Wolters, 2007; Burkhardt \& Schoenfeld, 2003; Kennedy, 1997). Another reason relates to different interests and goals between teachers and researchers, which ultimately call for two distinct types of knowledge (McIntyre, 2005): while researchers seek for generalizable and abstract propositions, teachers look for practical and concrete recommendations that can assist them in dealing

\footnotetext{
N. Pareja Roblin $(\square)$

University of Applied Sciences, Amsterdam, The Netherlands

e-mail: n.n.pareja.roblin@hva.nl

S. McKenney

Faculty of Behavioral, Management and Social Sciences, University of Twente,

Enschede, The Netherlands

e-mail: susan.mckenney@utwente.nl
} 
with the complexities and uniqueness of their classroom practice. A third commonly acknowledged reason pertains to the accessibility of research findings. The literature has suggested that teachers rarely use research to inform their practice because (i) academic journals are inaccessible to non-academic audiences (Hemsley-Brown \& Sharp, 2003), (ii) teachers lack the time to read research and make sense of it (Burkhardt \& Schoenfeld, 2003), and/or (iii) teachers experience difficulties in translating the rather general and abstract propositions of research findings into the specificities and peculiarities of their classroom practice (Broekkamp \& Van Hout-Wolters, 2007).

Different models to facilitate the diffusion and use of educational research have been developed and adopted over time. Three such models have commonly been identified in the literature: linear models, context-focused models, and interactive models (cf., Bauer \& Fischer, 2007; Landry, Amara, \& Lamari, 2001; Nutley, Walter, \& Davis, 2007). Linear models, also known as "science-push" models (Landry et al., 2001), emphasize the unidirectional flow of knowledge from research to practice (Nutley et al., 2007). Central to these models is the need to make research conceptually and physically accessible to teachers through various translation and dissemination efforts. Context-focused models, also known as "demandpull" models (Landry et al., 2001), focus on teachers' needs and on the contextual factors that shape the uptake of research. Although context-focused models allow for some degree of interaction between researchers and practitioners, this interaction is typically limited to the beginning (identification of needs and research problem) and the end (dissemination) of the research process (Bauer \& Fischer, 2007). Finally, interactive models emphasize the multidirectional flow of knowledge between researchers and teachers, each bringing their own values and perspectives (Nutley et al., 2007). Continuous involvement of teachers throughout the research process and not only at the beginning and/or at the end is thus regarded as essential (Bauer \& Fischer, 2007).

Although recent calls for strengthening research and practice relationships stress the need for new forms of collaboration and increased interaction between researchers and practitioners (de Vries \& Pieters, 2007; Farley-Ripple et al., 2018; Levin, 2013; Penuel, Allen, Coburn, \& Farrell, 2015), linear models have remained predominant for many decades (cf. Blakely et al., 1987; Posner, 2004; Schumacher, 1972; Thomas \& Pring, 2004). In this chapter, we examine a linear model that is prominently present in the design of curriculum innovations intended for large-scale implementation: the Research Development and Diffusion (RD\&D) model. The ultimate goal is to gain a better understanding of how research and practice relationships are shaped in RD\&D projects, and to ascertain whether and why the claimed benefits for and criticisms of this model are (still) warranted. 


\section{Theoretical Underpinnings}

\section{Characterizing the Research-Development-Diffusion Model}

The RD\&D model was conceived from the perspective of developing and implementing research-based curriculum innovations (Gottschalk et al., 1981 Havelock, 1969). RD\&D is generally characterized as being rationalistic, sequential, comprehensive and complex (Schumacher, 1972). It is rationalistic because it requires deliberate and systematic planning; sequential because research, development and diffusion activities follow a linear order; comprehensive because planning and development typically occur on a large scale; and complex because it requires the involvement of various participants and organizations. In the RD\&D model, the process of educational change is regarded as a systematic sequence of tasks that begins with the identification of a problem on the basis of a perceived need, then continues with the exploration and application of scientific principles for the development and evaluation of a research-based solution to this problem, and ultimately ends with the diffusion of the developed solution to the target group (Havelock, 1969; Posner, 2004).

Three distinct phases can be identified in the RD\&D model: research, development, and diffusion. The goal of the first phase, research, is to advance knowledge in the field. Although the research may or may not be directly concerned with a specific problem from educational practice, its results serve to inspire development activities. The second phase, development, aims at translating existing knowledge from research into the design of a solution for an actual problem. Along with design activities, the development phase typically includes the systematic testing and evaluation of the developed solution to assess its quality, utility, value and feasibility in natural settings. Finally, diffusion aims at facilitating dissemination and adoption. This third phase is typically broken down into specific activities aimed at creating awareness, demonstrating effectiveness and utility, and providing training and support (Clark \& Hopkins, 1969; Havelock, 1969).

Guba and Clark (in Havelock, 1969) argue that it is through this cycle of research, development and diffusion activities that the RD\&D model contributes to building stronger relationships between research and practice. Research utilization and dissemination play a key role in this process. Research utilization alludes to the application of (scientific) knowledge. In the RD\&D model, research utilization typically takes place when curriculum developers make deliberate use of relevant evidence from scientific research to inform the development of curriculum innovations. This knowledge, once embodied in curriculum frameworks and/or materials, needs to be communicated to the target users to facilitate acceptance and adoption through various dissemination activities. Hence, the effectiveness of the RD\&D model in 
connecting research and practice is dependent on both, successful research utilization and dissemination.

To understand the relationships between research and practice across RD\&D projects, three dimensions warrant consideration: (i) the participants involved throughout the RD\&D process and their roles, (ii) the types of knowledge used to inform the design of curriculum innovations; and (iii) the activities undertaken to facilitate diffusion and adoption. Taken together, these dimensions formed the analytical framework used in this study. In the next section we turn to each of these dimensions.

\section{A Framework for Analysing Research and Practice Relationships}

\section{Participants' Roles in RD\&D-Based Projects}

The core phases of research, development, and diffusion are often implemented by multiple (groups of) participants and organizations. Havelock (1969) distinguished three major roles in RD\&D projects, each related to a specific phase of the model: researcher, developer, and linkage agent. The researcher role consists of gaining a better understanding of an educational phenomenon, and thereby providing a general knowledge base that (potentially) can be used to inform development. The developer role, sometimes also undertaken by applied researchers, encompasses the design and evaluation of a solution to an identified problem. The linkage agent role entails the diffusion of the developed solution through various dissemination and training activities. Although the linear character of RD\&D has remained, over the years more emphasis has been given to involving teachers throughout the process, especially during development (Blakely et al., 1987).

\section{Types of Knowledge Informing Curriculum Design}

In $\mathrm{RD} \& \mathrm{D}$, one of the main sources informing the curriculum design process is the knowledge generated through scientific research. Developers are expected to search for and make use of relevant research knowledge (Brickell in Havelock, 1969). Knowledge generated through scientific inquiry can be communicated to the developers explicitly (e.g., through books, research articles) or implicitly (e.g., through personal interactions during coaching and supervision) (Nonaka \& Takeuchi, 1995). Besides the knowledge derived from the research literature, evidence collected during evaluation studies aimed at testing and assessing the overall quality of the curriculum innovation constitutes another key source of knowledge informing curriculum design (Havelock, 1969). The results of these evaluation studies are typically used to determine the utility and feasibility of the curriculum innovation in real settings, and hence they contribute to further adjustment of its characteristics to 
the context and needs of potential users. Finally, the RD\&D model also acknowledges that the development process can be informed by experience and intuition (Guba \& Clark in Havelock, 1969), increasingly recognized in the literature as another type of knowledge (Gibbons et al., 1994; Thomas \& Pring, 2004). The expertise of researchers, developers, content experts and/or practitioners can therefore be considered as a third source of knowledge that can potentially guide curriculum design.

\section{Diffusion}

In the traditional RD\&D model, diffusion is viewed as a one-way process, and hence has much in common with Rogers' (2003) model of diffusion of innovations. In this model, diffusion progresses through five main phases (Rogers, 2003): (1) knowledge (awareness that the innovation exists); (2) persuasion (interest in the innovation); (3) decision (adopt or reject); (4) implementation (trial); and (5) confirmation (continuing and or extending use). At the same time, the educational change research has emphasized the need to consider how stakeholders experience innovation and especially the diffusion/adoption process, and to design interventions accordingly (cf. Fullan, 2007; Hall \& Hord, 2010). This suggests the need for a bilateral relationship between development and diffusion.

Based on the framework described above, the current study aimed at gaining a better understanding of research and practice relationships across a set of studies reporting on the design of curriculum innovations featuring key characteristics of RD\&D as described above: systematically applying scientific principles for the development of a research-based solution to a perceived problem, following a linear sequence of research, development and diffusion activities, and involving various participants and organizations. The research questions guiding the study were:

1. What participants are involved in curriculum innovation projects featuring RD\&D characteristics, and what are their main roles?

2. What sources of knowledge are used to inform the design of curriculum innovations?

3. What activities are undertaken to facilitate diffusion and adoption of the curriculum innovations?

\section{Methods}

\section{Selection of Projects}

General descriptors distilled from the literature characterizing the RD\&D model were used to search for relevant projects, including terms reflecting the nature of the curriculum innovations under development (e.g., evidence-informed, 
evidence-based), terms related to the different phases of the research and development process (e.g., design, development, pilot study), and terms associated with the diffusion of curriculum innovations (e.g., dissemination, diffusion, adoption). The search was conducted in three scientific databases (ERIC, Scopus, Web of Science) and limited to articles published in 2008 and in 2009, to allow for in-depth analysis of projects featuring characteristics of the RD\&D model. This yielded a total of 1082 articles. Criteria used to select the projects are described in Table 2.1.

Abstracts were independently screened by two researchers and differences in judgement were discussed until agreement was reached. This procedure led to the identification of 181 studies that met the inclusion criteria. In the next step, the fulltext articles were screened using the same inclusion criteria, but paying particular attention to the presence of descriptions of how research informed the design of curriculum innovations. This step further reduced the sample to nine studies. The excluded studies did not explicitly address how research contributed to the design of the curriculum innovation. Most of them reported findings from evaluation studies, without documenting the process through which the curriculum innovation was developed or the ways in which findings from the evaluation studies contributed to informing further development cycles.

\section{Data Analysis}

A semi-structured template was developed to capture information extracted from each article concerning the project's characteristics (e.g., name, country, goals), the study design (e.g., research questions, data collection methods), and the types of curriculum innovations designed (e.g., curriculum framework, curriculum materials). Participant involvement was analyzed through the identification of participants' professions (e.g., researcher, teacher, content specialist) and roles (e.g., researcher, developer, trainer), and descriptions of the specific activities undertaken by each. References to the knowledge sources informing the design of curriculum innovations were coded as research literature, data collected through needs assessments and/or formative evaluations, or project team's practical knowledge. Activities undertaken to facilitate dissemination and adoption were analyzed by identifying

Table 2.1 Inclusion criteria

\begin{tabular}{l|l}
\hline Criteria & Description \\
\hline $\begin{array}{l}\text { Educational } \\
\text { orientation }\end{array}$ & $\begin{array}{l}\text { The project described was developed either within a formal educational setting } \\
\text { (i.e., primary, secondary or tertiary education) and/or as part of a teacher } \\
\text { professional development program }\end{array}$ \\
\hline Participants & $\begin{array}{l}\text { The project involved the participation of (student) teachers, university } \\
\text { researchers and/or teacher educators }\end{array}$ \\
\hline Research use & $\begin{array}{l}\text { The article discusses how research informed the design of curriculum } \\
\text { innovations, making explicit reference to the use of academic literature, results } \\
\text { from evaluation studies and/or the expertise of the project team }\end{array}$ \\
\hline Empiricism & The study reports the collection and analysis of empirical data \\
\hline
\end{tabular}


the main goal (e.g., develop ownership, create awareness, train teachers) and format (e.g., workshop, school meetings, curriculum materials) of each activity.

Common patterns and themes were identified across projects through constant comparison (cf. Denzin \& Lincoln, 2000). After analyzing all nine articles, findings were discussed first within the research team and then in a working conference involving scholars with expertise on (bridging) the research-practice gap.

\section{Findings}

\section{Characteristics of the Projects Included in the Review}

As illustrated in Table 2.2, the nine projects studied reflect ample variation in location, target educational level, and subject area, including projects from the USA $(n=4)$, The Netherlands $(n=3)$, Canada $(n=1)$, and Germany $(n=1)$. The target educational level ranged from pre-school to higher education. Almost half of the projects $(n=4)$ focused on physical education, while the remaining projects focused on diverse subject areas such as mathematics, cartography and pediatrics. All projects had a clear focus on the design of curriculum innovations intended for largescale use, a distinctive feature of the RD\&D model. Initiatives and/or conditions for systematically disseminating the innovation to a larger number of schools, teachers and students were explicitly addressed in all the studies.

Table 2.2 Overview of project characteristics

\begin{tabular}{|c|c|c|c|c|c|}
\hline $\begin{array}{l}\text { Type of } \\
\text { curriculum } \\
\text { innovation }\end{array}$ & Authors & Country & $\begin{array}{l}\text { Target } \\
\text { educational } \\
\text { level }\end{array}$ & Subject area & Phase reported \\
\hline \multirow[t]{4}{*}{$\begin{array}{l}\text { Curriculum } \\
\text { framework }\end{array}$} & $\begin{array}{l}\text { Balram and } \\
\text { Dragicevic }\end{array}$ & Canada & $\begin{array}{l}\text { Higher } \\
\text { education }\end{array}$ & Cartography & $\begin{array}{l}\text { Pilot } \\
\text { implementation }\end{array}$ \\
\hline & $\begin{array}{l}\text { Kittredge } \\
\text { et al. }\end{array}$ & USA & $\begin{array}{l}\text { Higher } \\
\text { education }\end{array}$ & Pediatrics & Dissemination \\
\hline & Stone et al. & USA & High school & Mathematics & $\begin{array}{l}\text { Summative } \\
\text { evaluation }\end{array}$ \\
\hline & Mooij & Netherlands & Pre-school & $\begin{array}{l}\text { Gifted } \\
\text { students }\end{array}$ & $\begin{array}{l}\text { Pilot } \\
\text { implementation }\end{array}$ \\
\hline \multirow{5}{*}{$\begin{array}{l}\text { Health } \\
\text { promotion } \\
\text { program }\end{array}$} & Berger et al. & Germany & High school & Not specified & $\begin{array}{l}\text { Formative } \\
\text { evaluation }\end{array}$ \\
\hline & Jurg et al. & Netherlands & $\begin{array}{l}\text { Primary } \\
\text { schools }\end{array}$ & $\begin{array}{l}\text { Physical } \\
\text { education }\end{array}$ & $\begin{array}{l}\text { Formative } \\
\text { evaluation }\end{array}$ \\
\hline & Jansen et al. & Netherlands & $\begin{array}{l}\text { Primary } \\
\text { schools }\end{array}$ & $\begin{array}{l}\text { Physical } \\
\text { education }\end{array}$ & $\begin{array}{l}\text { Summative } \\
\text { evaluation }\end{array}$ \\
\hline & Carlson et al. & USA & $\begin{array}{l}\text { Primary } \\
\text { schools }\end{array}$ & $\begin{array}{l}\text { Physical } \\
\text { education }\end{array}$ & $\begin{array}{l}\text { Formative } \\
\text { evaluation }\end{array}$ \\
\hline & $\begin{array}{l}\text { Williams } \\
\text { et al. }\end{array}$ & USA & Pre-school & $\begin{array}{l}\text { Physical } \\
\text { education }\end{array}$ & $\begin{array}{l}\text { Formative } \\
\text { evaluation }\end{array}$ \\
\hline
\end{tabular}


When looking at the nature of the curriculum innovations developed, two different types of projects can be identified. One type may be labeled as health promotion projects, and includes projects concerned with the development of school-based interventions focused on the primary prevention of eating disorders (Berger, Sowa, Bormann, Brix, \& Strauss, 2008) or on the promotion of physical activity and healthy nutrition (Carlson et al., 2008; Jansen et al., 2008; Jurg, De Meij, Van Der Wal, \& Koelen, 2008; Williams, Carter, Kibbe, \& Dennison, 2009). A second type may be labeled as curriculum framework projects and includes projects concerned with the development of frameworks to assist teachers in the design of innovative learning activities (Balram \& Dragicevic, 2008; Kittredge, Baldwin, Bar-On, Trimm, \& Beach, 2009; Mooij, 2008; Stone, Alfeld, \& Pearson, 2008).

\section{Participants' Roles}

Three major groups of participants can be identified across the nine projects: university researchers, content specialists (e.g., health care professionals, educational consultants, programming experts), and teachers. In addition to these groups, three projects (Berger et al., 2008; Jansen et al., 2008; Jurg et al., 2008) referred to the involvement of local organizations during implementation and/or diffusion activities (e.g., local health services, sport clubs). Even though slight variations can be identified across projects, the overall roles and activities within each of these groups of participants were largely comparable.

In all projects, university researchers adopted a central role in assessing the quality, utility, feasibility and/or effectiveness of the curriculum innovation. Hence, they were responsible for designing pilot and effectiveness studies, collecting data, and reporting findings. In addition to these activities, university researchers were actively involved in the design process, often in collaboration with content specialists. Moreover, a couple of projects referred to the role of university researchers as trainers (Williams et al., 2009) or facilitators (Mooij, 2008) who coached teachers and/or assisted other experts in teacher training activities during (pilot) implementation.

Along with university researchers, seven out of nine projects reported the participation of content specialists. These included educational consultants (Kittredge et al., 2009; Stone et al., 2008), partners for math teachers (Stone et al., 2008), and health care professionals (Berger et al., 2008; Carlson et al., 2008; Jansen et al., 2008; Jurg et al., 2008; Williams et al., 2009). The role of content specialists usually consisted of contributing to the design of the curriculum innovation (Carlson et al., 2008; Jurg et al., 2008; Kittredge et al., 2009; Stone et al., 2008; Williams et al., 2009), assisting researchers with data collection (Jansen et al., 2008), and/or providing professional advice to teachers and students during implementation (Berger et al., 2008; Carlson et al., 2008; Stone et al., 2008).

More than a half of the studies explicitly referred to teacher involvement in the design of the curriculum innovations, through their participation in the project team (Williams et al., 2009; Kittredge et al., 2009), their contributions to focus group 
discussions about their specific needs and viewpoints (Carlson et al., 2008), or their feedback on the quality and effectiveness of earlier prototype versions of the curriculum innovation (Jurg et al., 2008; Williams et al., 2009). In one project (Stone et al., 2008), teachers were actively involved in translating the curriculum framework developed by the research team into concrete lesson plans to be implemented in their own classrooms. Finally, two studies reported teacher involvement in disseminating information about the curriculum innovation to other teachers (Kittredge et al., 2009; Mooij, 2008).

The involvement of local organizations, such as municipal health services or sport clubs, was reported in three health promotion projects (Berger et al., 2008; Jansen et al., 2008; Jurg et al., 2008). When involved, these organizations were typically responsible for assisting teachers and project leaders with the implementation of sports activities, or for the diffusion of the program to a larger number of schools in the region.

\section{Sources of Knowledge Used to Inform the Design Process}

Table 2.3 presents an overview of the various sources of knowledge informing the design of the curriculum innovations. As it could be expected, in all projects the design process was largely informed by the scientific research literature. General theories derived from the fields of education (e.g., contextual learning, constructivism) and psychology (e.g., theory of planned behavior, social cognitive theory), as well as recent research findings related to the projects' particular area of focus (e.g., mathematics education, pediatrics, gifted students) guided curriculum design choices.

Table 2.3 Knowledge sources informing the development of curriculum innovations

\begin{tabular}{|c|c|c|c|c|c|}
\hline $\begin{array}{l}\text { Type of } \\
\text { curriculum } \\
\text { innovation }\end{array}$ & Author & $\begin{array}{l}\text { Research } \\
\text { literature }\end{array}$ & $\begin{array}{l}\text { Data from } \\
\text { needs } \\
\text { assessment }\end{array}$ & $\begin{array}{l}\text { Data from pilot } \\
\text { study/formative } \\
\text { evaluation }\end{array}$ & $\begin{array}{l}\text { Expertise of } \\
\text { multidisciplinary } \\
\text { team }\end{array}$ \\
\hline \multirow[t]{4}{*}{$\begin{array}{l}\text { Curriculum } \\
\text { framework }\end{array}$} & $\begin{array}{l}\text { Balram and } \\
\text { Dragicevic }\end{array}$ & $X$ & X & & \\
\hline & $\begin{array}{l}\text { Kittredge } \\
\text { et al. }\end{array}$ & X & X & $X$ & X \\
\hline & Stone et al. & $X$ & & & $X$ \\
\hline & Mooij & $X$ & & & \\
\hline \multirow{5}{*}{$\begin{array}{l}\text { Health } \\
\text { promotion } \\
\text { program }\end{array}$} & Berger et al. & $X$ & & X & \\
\hline & Jurg et al. & $X$ & & $X$ & \\
\hline & Jansen et al. & $X$ & & & \\
\hline & $\begin{array}{l}\text { Carlson } \\
\text { et al. }\end{array}$ & $X$ & $X$ & $X$ & \\
\hline & $\begin{array}{l}\text { Williams } \\
\text { et al. }\end{array}$ & $X$ & & X & \\
\hline
\end{tabular}

Note: $\mathrm{X}=$ used to inform the curriculum design process 
Along with relevant scientific research literature, six out of nine projects explicitly reported the use of data collected during the project to inform the curriculum design process. More specifically, data from needs assessments (Balram \& Dragicevic, 2008; Carlson et al., 2008; Kittredge et al., 2009) and/or formative evaluations (Berger et al., 2008; Carlson et al., 2008; Jurg et al., 2008; Kittredge et al., 2009; Williams et al., 2009) were instrumental in tailoring the curriculum innovations to the specific needs, expectations, motivation level, and/or educational background of potential users. Interestingly, only two projects (Kittredge et al., 2009; Stone et al., 2008) explicitly acknowledged that curriculum design was also informed by the practical knowledge of researchers and content specialists from various disciplines participating in the project team. Although the remaining projects also often involved experts from multiple disciplines, the ways in which their specific expertise informed the design process was not addressed in the articles.

In sum, scientific research knowledge typically shaped the development process in two ways. On the one hand, research literature and general educational or psychological theories were used to inform curriculum design choices. On the other hand, findings from needs assessments and/or formative evaluations were used to adjust the characteristics of the curriculum innovation to the context of implementation and to the specific needs and characteristics of potential users. By anticipating large-scale implementation through the identification of user needs and factors that could potentially influence later use, projects attempted to strengthen the relationships between research and practice.

\section{Diffusion Activities}

Across projects, various activities were systematically planned to facilitate the diffusion of the developed curriculum innovations. These activities aimed at generating a sense of ownership, creating awareness of the availability and benefits of the innovation among school staff and parents, and providing teachers with professional development and support.

\section{Teacher Ownership}

Over half of the projects $(n=5)$ reported active teacher involvement in the design process. Teacher involvement was encouraged in various ways across projects, including: (i) inviting teachers to participate in the project team (e.g., Williams et al., 2009) or in curriculum writing/reviewing subcommittees (e.g., Kittredge et al., 2009); (ii) organizing teacher teams to encourage the application of the curriculum framework in the design of enhanced lesson plans (e.g., Stone et al., 2008); and (iii) arranging focus group discussions (e.g., Carlson et al., 2008) or individual meetings (e.g., Mooij, 2008) to give teachers and other stakeholders the opportunity to express their viewpoints and concerns with regard to the (ideal) characteristics of 
the curriculum innovation. Despite the differences between these initiatives, they all shared the goal of facilitating active teacher engagement beginning at early stages in the design process.

\section{Awareness}

Activities to generate awareness about the need for and the benefits of the curriculum innovation among teachers, school staff and (particularly) parents were mainly reported across health promotion projects. Awareness was generally facilitated through school meetings (Berger et al., 2008; Jansen et al., 2008) and monthly newsletters (Carlson et al., 2008). During these activities, parents and school staff members received further information about the goals of the curriculum innovation, its characteristics and importance. Finally, in Williams et al. (2009), awareness of the innovation and its importance was encouraged by asking teachers to count their daily steps with the use of pedometers, thereby motivating them to increase their alertness regarding physical activity patterns in their students.

\section{Professional Development and Support}

Teacher training and support activities took the form of workshops (e.g., Kittredge et al., 2009; Stone et al., 2008), exemplary curriculum materials (Berger et al., 2008; Carlson et al., 2008; Jurg et al., 2008; Williams et al., 2009), demonstrations (e.g., Kittredge et al., 2009; Stone et al., 2008), and coaching (e.g., Mooij, 2008; Stone et al., 2008). Workshops were usually brief in duration (e.g., 1 or $2 \mathrm{~h}$ ) and were often led by a member of the project team. The goal of these workshops was to provide teachers with general information about the curriculum innovation and how it could be used in their own classrooms.

Exemplary curriculum materials were typically designed by the project team to assist teachers in the implementation of the curriculum innovation. These materials could include: a suite of instruments to follow up on students' physical activity together with a list of recommended school exercise activities (e.g., Jurg et al., 2008); copies of the curriculum and a list with instructions on how to use it (e.g., Carlson et al., 2008); curriculum units and exemplary physical activities (e.g., Williams et al., 2009); and/or posters and guidelines to encourage group discussions (e.g., Berger et al., 2008). Besides exemplary curriculum materials, demonstration activities were sometimes organized to provide teachers with the opportunity to see live examples of how the curriculum innovation could be implemented. Demonstrations took the form of showcase events (e.g., Kittredge et al., 2009) or teacher presentations (e.g., Stone et al., 2008).

Coaching activities took place during (pilot) implementation and aimed at supporting teachers with the use of the curriculum innovation. In the project described by Mooij (2008), the coaching role was adopted by the researcher himself, whereas in Stone et al. (2008), partners for math teachers adopted this role. Finally, Carlson 
et al. (2008) reported coaching activities in which graduate students from healthrelated professions (e.g., kinesiology, dietetics) acted as mentors/coaches of teachers and students during the implementation of the new learning activities.

\section{Discussion}

The present study aimed to explore how research and practice relationships materialize across curriculum innovation projects that feature core characteristics of the RD\&D model. These relationships were analyzed in relation to the participants involved in the project and their roles, the types of knowledge used to inform curriculum design, and the activities undertaken to facilitate diffusion and adoption. The rigorously defined set of articles that were included in our study provides a clear overview of what RD\&D-model based projects look like. Using this information, we discuss the contributions of the RD\&D model to strengthening research and practice relationships in education, as well as the criticisms of this model.

Overall, our findings confirm that the RD\&D model lives up to its potential to promote active utilization of scientific research for the development of curriculum innovations. All projects that were analyzed reported the use of scientific research literature as a major source of knowledge guiding the curriculum design process. In addition to this literature, the knowledge derived from systematic formative evaluation studies was central for tailoring the characteristics of the curriculum innovation to the context and needs of the target audience. Our findings also reveal that in some cases the design process was informed by the practical knowledge and expertise of the project team, particularly when design activities were undertaken by a multidisciplinary group. Notably, in over half of the studies, teachers' opinions, suggestions and practical experiences were used to inform the design process.

Another key finding of our study is concerned with the identification of the participants involved in RD\&D-based projects and their specific roles. Three different groups of participants were common to all projects: researchers, content specialists and teachers. This was to be expected from RD\&D projects. More surprising were the roles played by each of the participant groups. Teacher participation moved beyond the role of "consumers of research" typically attributed to them in the traditional RD\&D model. More than half of the projects analyzed reported some sort of teacher involvement in curriculum design, either reactively (e.g., by providing feedback after appraising prototypes of the educational solution) or proactively (e.g., by specifying their needs or translating the curriculum framework developed by researchers into concrete lesson plans). This indicates the presence of extended forms of communication between researchers and teachers throughout the RD\&D process. While in the traditional RD\&D model, communication was mainly characterized as being unidirectional and as primarily taking place at the diffusion phase of the RD\&D process, the projects studied show a tendency towards increased communication and (in some cases) collaboration between teachers and researchers from the early stages of the RD\&D process onwards. 
Researchers also adopted multiple roles. They were actively involved in the design of the curriculum innovations and were also responsible for assessing its quality, utility, feasibility and/or effectiveness in natural settings. In addition, in a couple of projects researchers were even involved in diffusion activities, adopting the role of teacher trainers or facilitators during (pilot) implementation. Hence, their responsibilities went far beyond carrying out the R in RD\&D. Similarly, content specialists' roles ranged from contributing with their knowledge and expertise during the curriculum design process, to providing professional advice during (pilot) implementation, to assisting researchers with data collection. This multiplicity of roles and activities reveals that, in contrast to the rather clear division of tasks suggested in the traditional RD\&D model, in the projects studied both the researchers and the content specialists have been actively involved across multiple phases. Further research could contribute to exploring how consistently this expanded role of researchers is observed, and how it contributes to strengthened research and practice relationships.

As mentioned at the start of this chapter, the RD\&D model and related evidencebased practices have long been strongly criticized for adopting a "teacher proof" approach (Biesta, 2010; Gottschalk et al., 1981; Posner, 2004; Schumacher, 1972). In contrast, the projects examined in this study actively involved teachers (e.g., teachers were invited to participate in the development team or in revision subcommittees); built in mechanisms for making site-specific modifications (e.g., data collected during formative evaluations was used to tailor the characteristics of the curriculum innovation to the needs, expectations, and background of potential users); and, assuming that adoption would be challenging, worked to render the innovations appealing and practical (e.g., teachers were provided with the opportunity to see how the curriculum innovation could be used in their classroom through demonstrations or teacher participation in communities of practice). Previous researchers have called for a modified RD\&D model that emphasizes the organizational and individual factors influencing implementation (Gottschalk et al., 1981), one that is grounded in a rigorous and systematic use of scientific research and evaluation methods, but also actively encourages involvement of practitioners in the design process (Blakely et al., 1987). Our study shows that the projects analyzed do exhibit these principles.

We see a need to disentangle the criticism of the RD\&D model from personal views concerning the goals and nature of research, the kinds of knowledge worth pursuing, and the acceptable methods for conducting scientific inquiry. Despite large epistemological differences between various approaches for bridging the research and practice gap, there seems to be increasing consensus about the need to intensify communication and collaboration among teachers, researchers and other stakeholders from the educational system (de Vries \& Pieters, 2007; Levin, 2013; Lieberman, 1992; Penuel et al., 2015). Our findings reveal that projects based on the modified RD\&D approach consider the needs of teachers and schools and involve them in the design process, although to different extents. This is a meaningful step forward in enabling new forms of communication between teachers and researchers. However, it should also be mentioned that most of the time, teachers' roles in 
the design process are still rather instrumental, insofar they are mainly considered in order to ensure successful implementation and "buy-in". We strongly encourage teacher involvement that extends to both knowledge use and knowledge production through active participation in research and design activities, as suggested by the teacher research (cf. Cochran-Smith \& Lytle, 1999) and design research (cf. McKenney \& Reeves, 2012) movements. Teacher adaptation of evidence-based practices would prevent the educational system from unwarranted expectations about the role of evidence in their practices and its uncritical use (Biesta, 2007, 2010).

Although the limited number of projects included in our study prevents us from making generalizations, the findings of the current study contribute a fresh look at the classic RD\&D model. Alongside the work of others (cf. Gottschalk et al., 1981), this study can inspire novel ways of thinking about core RD\&D assumptions, including: how to facilitate more active use of scientific research to inform curriculum development; the different ways the interactions between research, development and diffusion may be shaped; increased attention to the context; and new models of diffusion. Additionally, it can pave new paths for knowledge mobilization to let the educational system and particularly teachers benefit from the evidence produced by educational research (Levin, 2011). Yet, criticism of the RD\&D model is not without reason. Based on our study, we suggest that the problem lies not in the RD\&D model as a basic mechanism, but in narrow or outdated conceptualizations of the core processes (research, development and diffusion) and their interactions. This study provides both general findings and specific examples to spark discussions on what those processes can entail in fruitful RD\&D.

Acknowledgements We gratefully acknowledge the Netherlands Organisation for Scientific Research (NWO) for funding this study (Project Number 411-08-601). The authors also thank Bart Ormel for his contribution to data collection and analysis.

\section{References}

Balram, S., \& Dragicevic, S. (2008). Collaborative spaces for GIS-based multimedia cartography in blended environments. Computers \& Education, 50(1), 371-385.

Bauer, K., \& Fischer, F. (2007). The educational research-practice interface revisited: A scripting perspective. Educational Research and Evaluation, 13(3), 221-236.

Berger, U., Sowa, M., Bormann, B., Brix, C., \& Strauss, B. (2008). Primary prevention of eating disorders: Characteristics of effective programmes and how to bring them to broader dissemination. European Eating Disorders Review, 16(3), 173-183.

Biesta, G. (2007). Bridging the gap between educational research and educational practice: The need for critical distance. Educational Research and Evaluation, 13(3), 295-301.

Biesta, G. (2010). Why ‘what works' still won't work: From evidence-based education to valuebased education. Studies in Philosophy and Education, 29, 491-503. 
Blakely, C., Mayer, J., Gottschalk, R., Schmitt, N., Davidson, W., Roitman, D., et al. (1987). The fidelity-adaptation debate: Implications for the implementation of public sector social programs. American Journal of Community Psychology, 15(3), 253-268.

Broekkamp, H., \& Van Hout-Wolters, B. (2007). The gap between educational research and practice: A literature review, symposium and questionnaire. Educational Research and Evaluation, 13, 203-220.

Burkhardt, H., \& Schoenfeld, A. (2003). Improving educational research: Toward a more useful, more influential, and better-funded enterprise. Educational Researcher, 32(9), 3-14.

Carlson, J., Eisenmann, J., Pfeiffer, K., Jager, K., Sehnert, S., Yee, K., et al. (2008). (S)Partners for Heart Health: A school-based program for enhancing physical activity and nutrition to promote cardiovascular health in 5th grade students. BMC Public Health, 8, 1-12.

Clark, D., \& Hopkins, J. (1969). A report on educational research, development and diffusion manpower. Bloomington, IN: Indiana University Research Foundation.

Cochran-Smith, M., \& Lytle, S. (1999). Relationships of knowledge and practice. Teacher learning in communities. Review of Research in Education, 24, 249-305.

De Vries, B., \& Pieters, J. (2007). Bridging the gap between research and practice: Exploring the role of knowledge communities in educational change. European Educational Research Journal, 6(4), 382-392.

Denzin, N., \& Lincoln, Y. (Eds.). (2000). Handbook of qualitative research (2nd ed.). London: Sage Publications.

Farley-Ripple, E., May, H., Karpyn, A., Tilley, K., \& McDonough, K. (2018). Rethinking connections between research and practice in education: A conceptual framework. Educational Researcher, 47(4), 235-245.

Fullan, M. (2007). The new meaning of educational change. London: Cassell Educational Limited.

Gibbons, M., Limoges, C., Nowotny, H., Schwartzman, S., Scott, P., \& Trow, M. (1994). The new production of knowledge: The dynamics of science and research in contemporary societies. London: Sage.

Gottschalk, R., et al. (1981, October). Multi-site implementation and replication of research findings. Is the modified RD\&D model viable? Paper presented at a meeting of the Evaluation Research Society, Austin, TX.

Hall, G., \& Hord, S. (2010). Implementing change: Patterns, principles and potholes. Upper Saddle River, NJ: Prentice Hall.

Havelock, R. (1969). Planning for innovation: A comparative study of the literature on the dissemination and utilization of scientific knowledge. Ann Arbor, MI: Institute for Social Research, The University of Michigan.

Hemsley-Brown, J., \& Sharp, C. (2003). The use of research to improve professional practice. A systematic review of the literature. Oxford Review of Education, 29, 449-471.

Jansen, W., Raat, H., Zwanenburg, E., Reuvers, I., van Walsem, R., \& Brug, J. (2008). A schoolbased intervention to reduce overweight and inactivity in children aged 6-12 years: Study design of a randomized controlled trial. BMC Public Health, 8, 1-9.

Jurg, M., De Meij, J., Van Der Wal, M., \& Koelen, M. (2008). Using health promotion outcomes in formative evaluation studies to predict success factors in interventions: An application to an intervention for promoting physical activity in Dutch children (JUMP-in). Health Promotion International, 23(3), 231-239.

Kennedy, M. (1997). The connection between research and practice. Educational Researcher, 26(7), 4-12.

Kittredge, D., Baldwin, C. D., Bar-On, M., Trimm, R. F., \& Beach, P. S. (2009). One specialty's collaborative approach to competency-based curriculum development. Academic Medicine, 84(9), 1262-1268.

Landry, R., Amara, N., \& Lamari, M. (2001). Climbing the ladder of research utilization: Evidence from social science research. Science Communication, 22(4), 396-422.

Levin, B. (2011). Mobilizing research knowledge in education. London Review of Education, 9(1), 15-26. 
Levin, B. (2013). To know is not enough: Research knowledge and its use. Review of Education, $1(1), 2-31$.

Lieberman, A. (1992). The meaning of scholarly activity and the building of community. Educational Researcher, 21(6), 5-12.

McIntyre, D. (2005). Bridging the gap between research and practice. Cambridge Journal of Education, 35(3), 357-382.

McKenney, S., \& Reeves, T. (2012). Conducting educational design research. London: Routledge.

Mooij, T. (2008). Education and self-regulation of learning for gifted pupils: Systemic design and development. Research Papers in Education, 23(1), 1-19.

Nonaka, I., \& Takeuchi, H. (1995). The knowledge-creating company. Oxford, UK: Oxford University Press.

Nutley, S., Jung, T., \& Walter, I. (2009). The many forms of research-informed practice: A framework for mapping diversity. Cambridge Journal of Education, 38(1), 53-71.

Nutley, S., Walter, I., \& Davies, H. (2007). Using evidence. How research can inform public services. Bristol, UK: The Policy Press.

Penuel, W. R., Allen, A. R., Coburn, C. E., \& Farrell, C. (2015). Conceptualizing research-practice partnerships as joint work at boundaries. Journal of Education for Students Placed at Risk (JESPAR), 20(1-2), 182-197.

Posner, G. (2004). Analyzing the curriculum (3rd ed.). New York: McGraw Hill.

Rogers, E. (2003). Diffusion of innovations (5th ed.). New York: Free Press.

Schumacher, S. (1972, November). Limitations of a research, development and diffusion strategy in diffusion: A case study of nine local implementations of state-adopted curriculum. Paper presented at the National Council for the Social Studies Annual Meeting, Boston.

Stone, J., Alfeld, C., \& Pearson, D. (2008). Rigor "and" relevance: Enhancing high school students' math skills through career and technical education. American Educational Research Journal, 45(3), 767-795.

Thomas, G., \& Pring, R. (2004). Evidence-based practice in education. Maidenhead, UK: Open University Press.

Vanderlinde, R., \& van Braak, J. (2010). The gap between educational research and practice: Views of teachers, school leaders, intermediaries and researchers. British Educational Research Journal, 36, 299-316.

Williams, C., Carter, B., Kibbe, D., \& Dennison, D. (2009). Increasing physical activity in preschool: A pilot study to evaluate animal trackers. Journal of Nutrition Education and Behavior, 41(1), 47-52.

Open Access This chapter is licensed under the terms of the Creative Commons Attribution 4.0 International License (http://creativecommons.org/licenses/by/4.0/), which permits use, sharing, adaptation, distribution and reproduction in any medium or format, as long as you give appropriate credit to the original author(s) and the source, provide a link to the Creative Commons licence and indicate if changes were made.

The images or other third party material in this chapter are included in the chapter's Creative Commons licence, unless indicated otherwise in a credit line to the material. If material is not included in the chapter's Creative Commons licence and your intended use is not permitted by statutory regulation or exceeds the permitted use, you will need to obtain permission directly from the copyright holder.

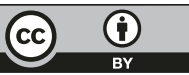

